\title{
O uso da exposição científica "Comer para viver" como atividade não formal para educação em saúde
}

\author{
The use of the scientific exhibition "Eat to live" as a non-formal activity for \\ health education
}

\author{
Wislaine Cardoso de Oliveira (D) https://orcid.org/0000-0003-3436-1990 \\ Universidade Federal do Mato Grosso \\ E-mail: wislainecardoso@gmail.com \\ Lorenna Cardoso Rezende (iD) https://orcid.org/0000-0003-2058-4333 \\ Universidade Federal do Mato Grosso \\ E-mail: lorisunb@gmail.com \\ Clarianna Martins Baicere Silva (D) https://orcid.org/0000-0001-6072-4930 \\ Universidade Federal do Mato Grosso \\ E-mail: clariannamartins@gmail.com
}

\section{Resumo}

Este trabalho surgiu do interesse em compreender o quanto a interação dos visitantes com o espaço não formal de aprendizado poderia significar para a apropriação do conhecimento disponível por meio do material expográfico. O objetivo deste estudo foi analisar as concepções sobre o sistema digestório e a alimentação humana elaboradas pelos alunos do ensino fundamental após visitarem a exposição "Comer para Viver" da Universidade Federal de Mato Grosso, campus Sinop. Os participantes da pesquisa foram 31 estudantes com idade entre 12 a 13 anos, divididos em três grupos, cursando o sétimo ano do ensino fundamental da Escola Estadual Djalma Guilherme da Silva, localizada no município de Sinop. A coleta de dados foi realizada por meio de roda de conversa com cada grupo separadamente, durante o período de aula e no dia determinado pela professora da classe. Utilizou-se a análise de conteúdo, que a partir dos diálogos registrados constituiu-se o corpus de análise e a interpretação do fenômeno. A exposição "Comer para viver" oportunizou a divulgação científica e a popularização do conhecimento, porque pela análise das falas dos estudantes percebeu-se que eles se apropriaram dos conceitos científicos e até divulgaram o que aprenderam entre os seus familiares. Alguns participantes inclusive relataram mudanças de hábito após visitar a exposição.

Palavras-chave: Saúde e educação. Educação não formal. Material didático. 


\begin{abstract}
This research arose from the interest to understand how much the interaction of visitors with the non-formal learning space could mean for the available knowledge appropriation by the expographic material. The aim herein was to analyze the conceptions about the digestive system and human food developed by elementary school students after visiting the exhibition "eat to live" at the Federal University of Mato Grosso, Sinop, Brazil. The sample was composed of 31 students from the seventh grade of Djalma Guilherme da Silva elementary school, located in the municipality of Sinop. These students were 12 to 13 years old and were divided into three groups. Data collection was carried out through a conversation circle, during the class time and on a day determined by the teacher. Content analysis was performed to constitute the corpus of analysis and proceed with the interpretation of the phenomenon from the registered dialogues. The "Eat to live" exhibition provided an opportunity for scientific dissemination and knowledge popularization. By the analysis of the students' speeches, we observed that they appropriated of scientific concepts and even divulged what they learned among their families. Some participants even reported habit changes after visiting the exhibition.
\end{abstract}

Keywords: Health and education. Non formal education. Didactical materials.

\title{
Introdução
}

O termo 'divulgação científica' pode ser compreendido como uma atividade na qual visa explicar ou disseminar conhecimentos relacionados à cultura, pensamento científico e técnico, ocorrendo fora do sistema de ensino com pretensão de atingir um público leigo através de uma linguagem coloquial (CARIBÉ, 2011). No Brasil, esse termo é entendido por alguns autores brasileiros como alfabetização científica e/ou letramento científico. Magda Soares (2007), em seu livro "Letramento: um tema em três gêneros", afirma que o termo "letramento" foi empregado no Brasil na segunda metade da década de 1980. A autora supracitada diferencia a alfabetização e o letramento científico. Segundo ela, um cidadão alfabetizado é aquele que aprende a ler e escrever cientificamente e quando faz uso desse saber nas práticas sociais ele se torna letrado. O conteúdo científico pode ser popularizado nas diversas áreas do saber como na saúde, informática, cultura, política, dentre outras (CARVALHO, 2009).

\section{A importância dos espaços museais para promover a educação em saúde}

Os espaços museais nem sempre tiveram a intenção de promover a educação, pelo contrário, na idade antiga, de acordo com Suano (1986), os objetos eram colecionados, simbolizando riqueza e poder. Apesar de muitas pessoas ainda entenderem museus como espaços para colecionar peças históricas, eles também podem assumir a função de divulgação e popularização do conhecimento científico (FALK, STORKSDIECK, 2005; ROCHA, 2008, BIZERRA, MARANDINO, 2009; SOUZA, 2015). Na contemporaneidade surge outra geração de museus, que se 
diferenciaram por realizarem exposições que apresentam ideias ao invés de objetos (MCMANUS, 1992).

As instituições museais têm como principal objetivo divulgar o conhecimento científico em uma linguagem de forma acessível (ROCHA, 2008). Ideia também trazida pelo Programa de Educação em Saúde do Governo Federal, que visa a apropriação do conhecimento científico pela população para aumentar a autonomia dos indivíduos no cuidado do próprio corpo (BRASIL, 2012). Dessa forma, levando em consideração que a execução deste Programa não se restringe somente às Unidades Básicas de Saúde, os centros de ciências também podem proporcionar uma significante contribuição à sua promoção (CRUZMAN; SIQUEIRA, 2007).

No Brasil, existem vários museus que utilizam seus espaços para educar em saúde, como o Museu da Vida da Casa de Oswaldo Cruz/FIOCRUZ, Instituto Butantan, Museu de Saúde Pública Emílio Ribas, dentre outros (CRUZMAN; SIQUEIRA, 2007). Na categoria da saúde, área de interesse deste trabalho, Sorensen (2012), afirma que consiste na capacidade dos cidadãos em obter, processar e interpretar informações básicas usadas com a finalidade de tomar decisões adequadas para resolver problemas básicos relacionados a saúde e alimentação. Para Baker (1998) e Paskulin (2012) esta categoria surgiu para melhorar e promover o acesso da população sobre informes relacionados aos cuidados com a saúde e prevenção de doenças. Em contrapartida, a baixa literacia em saúde é frequentemente acompanhada de menor capacidade de entender como prevenir doenças e promover saúde (BAKER, 1998).

Todavia, o objetivo da educação museal vai muito além de apenas proporcionar a divulgação científica (ROCHA, 2008). O espaço museológico é compreendido como uma instituição educativa singular, já que apresenta não apenas a intenção de ensinar e produzir aprendizagem, mas também é um depositário de elementos que permitem a reflexão e a construção de uma nova ideia conceitual (MATOS, 2014).

De acordo com Scheiner (2008), o espaço museal pode levar os visitantes a possuírem atos reflexivos em detrimento de atitudes contemplativas. Esses espaços envolvem-se em um plano afetivo, onde a mente e o corpo se mobilizam em conjunto, abrindo a mente para adquirir novos saberes, proporcionando no fim, novas visões de mundo e possibilidades de percepção. De acordo com Libâneo (2004), a educação formal e a não formal se diferenciam, porque a primeira apresenta planejamento, estruturação, organização e sistematização do ensino, diferente da não formal que possui baixo grau de estruturação e sistematização.

Cazelli, Marandino e Studart (2003) afirmaram que os museus e os centros de ciências são espaços educativos não formais, os quais são capazes de oferecer condições favoráveis ao desenvolvimento de atividades interativas, de caráter lúdico e de divulgação científica. Além de ser possível organizar atividades que englobam, ao mesmo tempo, diversas áreas do conhecimento e a interdisciplinaridade tornando-as naturais e mais acessíveis (BORTOLETTO, 2013).

$\mathrm{Na}$ definição de museus, essas instituições tem o intuito de promover a educação (ICOM, 2015). Portanto, Bizerra (2009) ao considerar que nesses espaços tem a função educacional, sugere-se que neles também é possível ocorrer a aprendizagem e as peças expositivas tornam-se elementos relevantes deste processo. Nesse sentido, para Vasconcelos e Manzi (2017) a aprendizagem pode 
ser entendida como processo cognitivo em que o indivíduo constrói o conhecimento, desenvolvendo de forma autônoma sua visão de mundo.

Em suma, o que é chamado de aprendizagem nesses ambientes, então, é a identificação e a caracterização das possíveis influências que estes espaços com todas as suas peculiaridades podem contribuir para formação de novas concepções (ROCHA, 2008).

Com relação às teorias de aprendizagem que influenciam as exposições científicas, pode-se apontar a construtivista como a mais relevante nas últimas três décadas, em virtude de enfatizar a função dos sujeitos serem seres ativos no processo de construção do seu aprendizado, além de considerar o meio como um elemento significativo neste processo, uma vez que necessita haver interação entre o indivíduo e o ambiente em que ocorre a aprendizagem, as ideias de Piaget sobre o desenvolvimento cognitivo e Lev Vygotsky sobre o papel das interações sociais no processo de aprendizagem, dentre outras, influenciaram e continuam influenciando as abordagens educacionais das exposições (CAZELLI, MARANDINO $E$ STUDART, 2003). Esta foi a abordagem embasada para analisar os diálogos registrados, a fim de descrever o nível de apropriação dos conceitos científicos pelos sujeitos da pesquisa após a visitação à exposição. Esta teoria está fundamentada na filosofia cognitivista, na qual tem sua ênfase em descobrir como os indivíduos conhecem o mundo. Nela a aprendizagem é caracterizada pelos processos mentais que ocorrem na mente humana, levando em consideração a atribuição de significados, a compreensão, transformação, armazenamento e utilização da informação envolvida na cognição (MOREIRA, 1999).

\section{Conhecimento dos estudantes sobre as diversas partes do corpo}

O currículo do ensino fundamental de acordo com a Base Nacional Curricular Comum elenca como objetivo de conhecimento os "programas e indicadores de saúde pública", portanto a escola deve selecionar saberes que visem a compreensão do corpo humano como um todo e que a sua manutenção depende do funcionamento de cada segmento corporal (BRASIL, 2019). Nos anos iniciais, pretende-se que as crianças ampliem os seus conhecimentos pelo seu corpo, identificando os cuidados necessários para a manutenção da saúde e integridade do organismo, já nos anos finais os estudantes devem ser capazes de argumentar sobre a importância da imunização e interpretar as condições de saúde da comunidade através dos indicadores de saúde, como taxa de mortalidade, saneamento básico dentre outros (BRASIL, 2019).

No entanto, o desafio encontra-se em transformar essa proposta pedagógica em ações que gerem mudanças na vida dos sujeitos, seja no ensino intencional ou não intencional (ROCHA, 2008).

Com base nessa nova configuração de exposição científica, esse trabalho tem como objetivo analisar as concepções sobre o sistema digestório e a alimentação humana elaboradas pelos alunos do ensino fundamental da Escola Estadual Djalma Guilherme da Silva, localizada no município de Sinop-Mato Grosso que visitaram a exposição "Comer para Viver" na Universidade Federal do Mato Grosso, campus Sinop. 


\section{Percurso da pesquisa: procedimentos metodológicos}

A exposição científica "Comer para Viver" foi criada na Universidade Federal do Mato Grosso (UFMT), campus Sinop, tendo como o eixo temático o sistema digestório humano e a alimentação, o material expográfico produzido foi disposto espacialmente para que os visitantes passassem por todos os ambientes, simulando o percurso do bolo alimentar: cavidade oral, estômago e intestino (figura 1).

Figura 1- Imagens da exposição científica "Comer para Viver". A- Entrada da exposição. BEstação da cavidade oral. C- Estação de glândulas anexas. D- Estação do estômago. E- Estação do intestino delgado e grosso. F- Estação de alimentação "Feirinha Viva Mais".
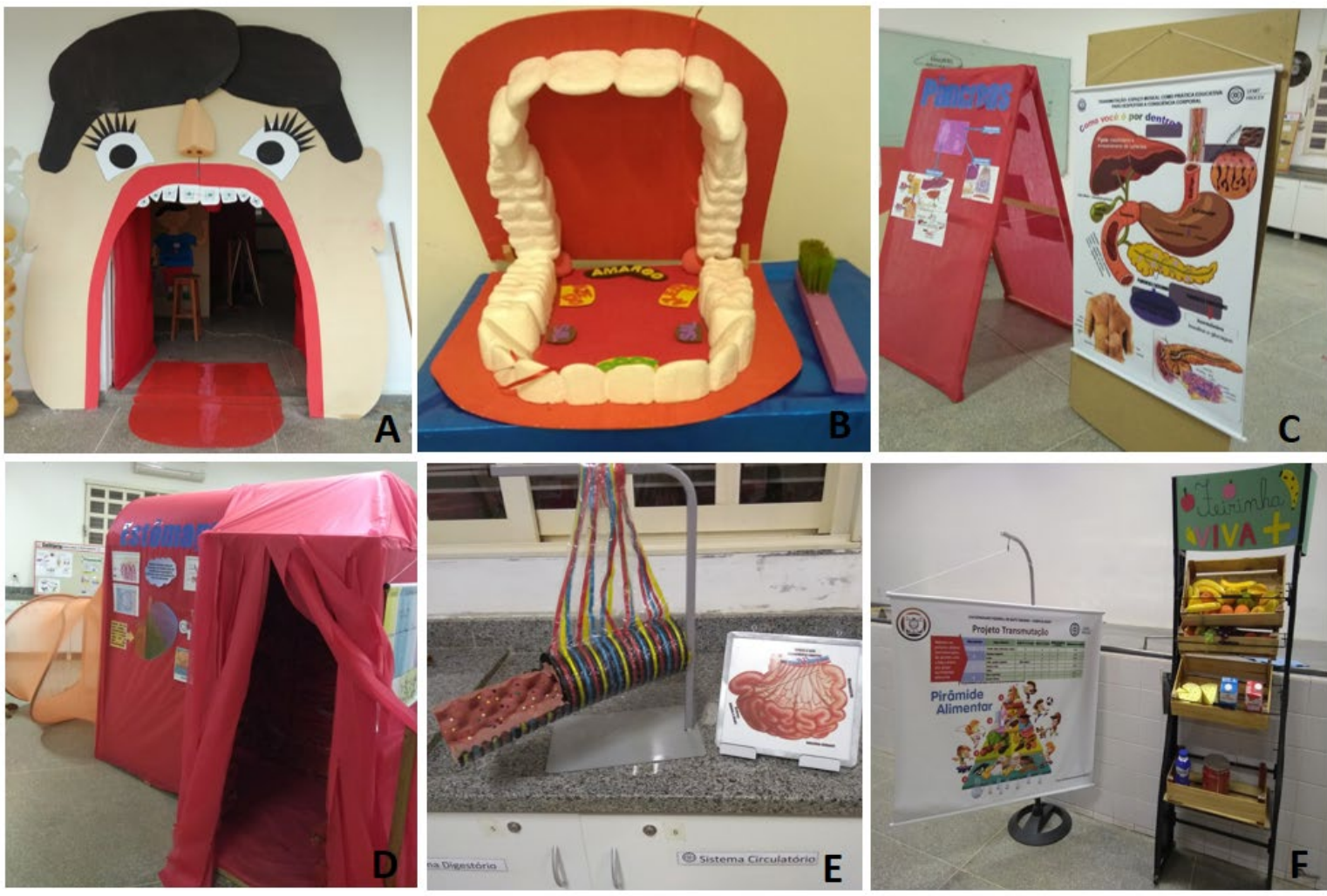

Fonte: Elaboração própria

A exposição foi aberta ao público interno e externo da UFMT com a intenção de promover a divulgação científica. Nesse sentido, trabalhou-se numa perspectiva interdisciplinar; mesclando conceitos biológicos, físicos e químicos; privilegiando o aspecto lúdico, a interatividade, a alfabetização e letramento científico, fomentando, desse modo, a cultura científica. Os assuntos abordados foram: a importância da higienização das mãos, alimentos e mastigação, a função dos órgãos que compõem o sistema digestório, o papel da microbiota intestinal e as principais doenças parasitárias.

O espaço foi organizado de modo a conduzir os visitantes na sequência do tubo digestório. Os visitantes transpunham um pórtico que representava a cabeça de uma criança com a boca aberta, identificada como "Caio" com o intuito de que os visitantes se imaginassem entrando dentro do sistema digestório humano (Figura 1A). Assim que adentravam para a cavidade bucal atravessavam um túnel que fazia alusão a faringe, seguiam pela boca (Figura 1B), estômago (Figura 1C), glândulas 
anexas (pâncreas e fígado) (Figura 1D), intestino delgado e grosso (Figura 1E) e, por fim, a feira "Viva mais" onde trabalhava-se a importância da alimentação saudável (Figura 1F). Os mediadores foram distribuídos estrategicamente pelo espaço facilitando o auxílio dos sujeitos no processo de construção do conhecimento.

A pesquisa que deu origem a esse artigo se caracterizou como um estudo exploratório e descritivo, com abordagem qualitativa.

O público alvo dessa pesquisa foi uma classe de alunos do Ensino Fundamental da Escola Estadual Djalma Guilherme da Silva, localizada no município de Sinop-Mato Grosso. Os sujeitos da pesquisa foram 31 alunos regularmente matriculados no sétimo ano, turma $\mathrm{C}$, com 12 a 13 anos de idade, que visitaram a exposição "Comer para viver" ocorrida na UFMT, campus Sinop. Destes, 11 indivíduos eram do gênero feminino e 20 do gênero masculino, sendo que do total, 6 alunos residiam na zona rural e 25 na zona urbana, mais especificamente nas zonas periféricas e de baixa renda.

Os dados desta pesquisa foram levantados com a realização de roda de conversa, trinta dias após a visitação. A coleta de dados ocorreu por meio da fala e escuta o que permitiu que todos os participantes expressarem suas ideias, opiniões, concepções sobre o tema proposto, em uma dinâmica de interações. Os alunos que não compareceram no dia estabelecido para a realização da coleta de dados foram excluídos da pesquisa. Deste modo, ao final houve 09 exclusões.

A data e o período para realizar a roda de conversa foi estabelecido e disponibilizado pela docente responsável pela turma C. Na visitação à exposição, a turma foi subdividida em três grupos de no máximo 10 alunos, visto que o espaço não comportava receber ao mesmo tempo mais pessoas. A equipe do projeto manteve esta divisão para realizar as rodas de conversa, as quais foram executadas de modo consecutivo. Assim, enquanto um grupo estava na roda de conversa, os outros permaneceram em sala de aula com a professora. O período para a execução das rodas de conversa foi das $13 \mathrm{~h} 00 \mathrm{~min}$ às $15 \mathrm{~h} 00 \mathrm{~min}$, portanto, foi padronizado o intervalo de 35 minutos para os três grupos.

Em relação aos perfis dos grupos, o primeiro foi composto por 05 sujeitos. Observou-se que estes alunos eram majoritariamente tímidos e tinham dificuldades em se expressar verbalmente. O segundo foi composto por 09 sujeitos que participaram ativamente da roda de conversa, os quais competiam entre si para responder os questionamentos, já o terceiro foi composto por 08 sujeitos com comportamento mais introvertido quando comparado com os demais.

A execução da roda de conversa ocorreu no laboratório de Língua Brasileira de Sinais - LIBRAS da UFMT, por ser este espaço apropriado para realizar filmagens e estar localizado no mesmo prédio da escola. No ambiente, foram montadas duas filmadoras para captar imagens e sons das respostas e a interação dos participantes, que posteriormente foram objeto de avaliação. Na roda de conversa, o diálogo foi conduzido por duas mediadoras. O restante da equipe auxiliou no manuseio dos equipamentos, chegada e saída dos alunos no laboratório.

Como instrumento de coleta de dados, foram estruturadas perguntas relacionadas com a alimentação e o funcionamento do corpo humano e aplicadas no decorrer da dinâmica desenvolvida durante a roda de conversa, utilizando-se o jogo do quebra- 
cabeça, no qual foi solicitado aos sujeitos montarem as peças dos órgãos do sistema digestório no tabuleiro em forma de avental, replicando a metodologia aplicada durante a exposição, com a intenção de avaliar o grau de apropriação do conteúdo.

A Análise de Conteúdo (AC) foi utilizada para, a partir dos registros, constituir o corpus de análise e proceder a elaboração de uma interpretação do fenômeno, seguindo a metodologia da pesquisadora Laurence Bardin (2011). Os resultados e a discussão foram divididos em duas categorias de análise, sendo elas: a influência da visitação na percepção da morfofisiologia do sistema digestório e relatos das lembranças dos visitantes sobre a exposição "Comer para viver".

\section{Resultados e discussão}

A seguir apresenta-se os resultados da pesquisa, interpretando os relatos dos grupos e discutindo com a literatura científica.

\section{A influência da visitação na percepção da morfofisiologia do sistema digestório}

$\mathrm{Na}$ exposição, todos os visitantes tiveram acesso aos nomes e posicionamento dos órgãos, como também a visitação em todas as estações do espaço.

No momento da roda de conversa os grupos se expressaram de forma diferente, mas, na essência, conseguiram nomear e montar as peças do jogo do quebracabeça (Quadro 1), dialogando e trabalhando em equipe responderam às perguntas realizadas.

Quadro 1- Respostas obtidas sobre a função dos órgãos do sistema digestório.

\begin{tabular}{|c|c|c|c|}
\hline ORGÃOS & GRUPO 1 & GRUPO 2 & GRUPO 3 \\
\hline BOCA & "Tritura, mastiga" & $\begin{array}{l}\text { "Ela tritura os } \\
\text { alimentos" }\end{array}$ & $\begin{array}{l}\text { "Tritura, mastiga e } \\
\text { corta os alimentos" }\end{array}$ \\
\hline ESTÔMAGO & $\begin{array}{l}\text { "Ele é o triturador que } \\
\text { bate tudo, daí" }\end{array}$ & $\begin{array}{l}\text { "É um líquido que } \\
\text { derretia tudo } \\
\text { mano[...]" }\end{array}$ & $\begin{array}{l}\text { "Ele tipo macera [...] } \\
\text { num sei falar [...]tipo } \\
\text { a boca tritura os } \\
\text { alimentos, ai o } \\
\text { estômago vai lá e } \\
\text { diminui mais ainda" }\end{array}$ \\
\hline PÂNCREAS & $\begin{array}{l}\text { "Ele que libera dois } \\
\text { hormônios né?" }\end{array}$ & $\begin{array}{l}\text { "É o negócio que } \\
\text { solta o negócio da } \\
\text { diabete véi"e "Ele } \\
\text { serve pra calcula o } \\
\text { quanto de açúcar tem } \\
\text { no sangue não é?" }\end{array}$ & $\begin{array}{l}\text { "Não é aquele } \\
\text { negócio lá que corta } \\
\text { o açúcar?", outro } \\
\text { falou "Tem alguma } \\
\text { coisa a ver com } \\
\text { insulina", "Pra } \\
\text { equilibrar" e "Ele } \\
\text { transforma em } \\
\text { energia, num é?" }\end{array}$ \\
\hline FÍGADO & $\begin{array}{l}\text { "Tirar a gordura" e "É } \\
\text { o detergente!" }\end{array}$ & $\begin{array}{l}\text { "É para produzir o } \\
\text { detergente"e "A bile" }\end{array}$ & $\begin{array}{l}\text { "[...] faz a bílis [...]", } \\
\text { "Bile", “[...] meio que } \\
\text { corta as } \\
\text { gorduras"e"[...] tem }\end{array}$ \\
\hline
\end{tabular}




\begin{tabular}{|l|l|l|l|}
\hline & & $\begin{array}{l}\text { os ductos [...], que } \\
\text { faz a conexão com o } \\
\text { intestino" }\end{array}$ \\
\hline INTESTINOS & $\begin{array}{l}\text { "Ele suga a água e } \\
\text { depois ele devolve a } \\
\text { água" }\end{array}$ & $\begin{array}{l}\text { "Ele é só pra finalizar } \\
\text { oliquido e essas } \\
\text { coisas"e "Forma as } \\
\text { fezes" }\end{array}$ & $\begin{array}{l}\text { "Pra tipo absorver os } \\
\text { nutrientes" e "Ele vai } \\
\text { efaz uma suç̧ão } \\
\text { final" }\end{array}$ \\
\hline
\end{tabular}

Fonte: Elaboração própria

As respostas foram semelhantes apresentando peculiaridades, sugerindo que os sujeitos não decoraram as informações, mas conseguiram se apropriar do conteúdo e até formulando ideias relacionaram ao conteúdo e suas vivências sobre a temática abordada. Nas exposições científicas o visitante tem total autonomia no processo de assimilação cognitiva, sendo assim, ele escolhe o quê e quando aprender (FIQUEROA; MARANDINO, 2013), fenômeno nítido observado nas diferenças de respostas entre os grupos.

Com relação ao fígado, o mediador na exposição usou uma metáfora, comparando a vesícula biliar com o litro de detergente e o seu conteúdo com a bile. Durante a roda de conversa, a pesquisadora perguntou aos sujeitos de cada grupo o que eles lembravam sobre o fígado. Assim, de acordo com os resultados descritos anteriormente, pôde-se observar que os grupos 1 e 2 repetiram a metáfora utilizada pelo mediador da exposição, confirmando a ideia de outros autores (FALK; STORKSDIECK, 2005) de o mediador habilitado ser um elemento importante no processo de aprendizagem.

$\mathrm{Na}$ roda de conversa o grupo 1 e o 2 reproduziram a metáfora. No entanto, é interessante ressaltar que alguns sujeitos se apropriaram de mais conceitos presente naquela estação, por exemplo, mencionando os ductos biliares e a função bile emulsificando a gordura.

No processo de digestão, sabe-se que os alimentos são reduzidos em partículas menores pelo suco gástrico, formando o quimo. O mediador da exposição, além de apresentar os nomes científicos, usou a ludicidade para relacionar a digestão do estômago com a mistura realizada por um liquidificador. Na roda de conversa, um sujeito do grupo 1 descreveu a ação desse órgão: "[...] ele é o triturador que bate tudo daí", observando-se que a alusão do mediador durante a exposição foi importante para a apropriação do conteúdo. Assim colaborando com Santos (2010) em que afirmou que o lúdico denotava ilusão envolvendo a imaginação, capacidade de compreensão e desenvolvimento cognitivo, representando um estímulo para a aprendizagem.

A mediadora da roda de conversa perguntou o que chamou a atenção deles no túnel do estômago, obtendo a seguinte resposta: "Algumas luizinhas", então foi-lhes questionado o que elas representavam, e eles afirmaram: "As células", portanto, concluiu-se que os sujeitos conseguiram relacionar as luzes com as células. Sobre o que essas células produziam um sujeito afirmou " $E$ um líquido que derretia tudo, mano", e outro com tom de dúvida disse "Não é o líquido que ajuda a digerir os alimentos?", logo a seguir, tentaram lembrar o nome do ácido, mas não obtiveram êxito. Assim, corroborando a ideia de Oliveira (2009) de que atividade lúdica facilita o aprendizado dos indivíduos, não devendo ser interpretada somente como lazer ou 
divertimento, os alunos entenderam a localização das células e o seu mecanismo de ação, apesar de não lembrarem o nome da substância produzida pelas células.

Cazelli, Marandino e Studart (2003) afirmaram que as exposições científicas são espaços não formais de educação e ampliaram significativamente o "alfabetismo científico". Nos resultados dessa pesquisa, foi possível observar o desenvolvimento deste alfabetismo, visto que em muitos relatos, os sujeitos verbalizaram conceitos sobre o sistema digestório, os quais foram mencionados na visitação, tanto pelos mediadores, como no material expográfico. Esses ganhos cognitivos podem ser consequências de simples assimilação do conteúdo ou de uma reestruturação cognitiva prévia, conforme apontado por Anderson, Lucas e Ginns (2003). Com relação à nominação e posicionamento dos órgãos existiram dúvidas, contudo, eles dialogavam entre si, algumas vezes com o auxílio da mediadora, mas geralmente chegavam à resposta adequada.

Nesse sentido, apresenta-se no Quadro 2, as expressões corretas e incorretas narradas de acordo com a condução da roda de conversa por órgãos do sistema digestório.

Observa-se que os termos incorretos se aproximaram do verdadeiro nome, o que significa que os sujeitos se apropriaram de parte significativa dos conceitos trabalhados.

Quadro 2- Expressões classificadas em corretas e incorretas referentes a cada órgão trabalhado do sistema digestório, retiradas dos diálogos dos três grupos analisados nas rodas de conversa com o sétimo ano, turma C, da Escola Djalma Guilherme da Silva, em 2019.

\begin{tabular}{|c|c|c|}
\hline \multirow{2}{*}{ ÓRGÃO } & \multicolumn{2}{|c|}{ EXPRESSÕES } \\
\hline & CORRETAS & INCORRETAS \\
\hline Esôfago & - & Esôfago \\
\hline \multirow{5}{*}{ Estômago } & \multirow{5}{*}{$\begin{array}{l}\text { Não é um líquido que ajuda a digeri } \\
\text { os alimentos? }\end{array}$} & Suco gástrico \\
\hline & & Ácido clorético \\
\hline & & Ácidu clofídrico \\
\hline & & Ele tipo macera \\
\hline & & É um líquido que derretia tudo mano \\
\hline \multirow{3}{*}{ Pâncreas } & Insulina & $\begin{array}{l}\text { Ele serve pra "calculá" o quanto de açúcar } \\
\text { tem no sangue, num é? }\end{array}$ \\
\hline & \multirow{2}{*}{$\begin{array}{l}\text { Ela tira o açúcar do sangue para } \\
\text { colocar nas células, pra da energia } \\
\text { pra elas, pra elas fazerem um monte } \\
\text { de coisas }\end{array}$} & $\begin{array}{l}\text { É o negócio que solta o negócio da } \\
\text { diabete véi }\end{array}$ \\
\hline & & Diabetes \\
\hline \multirow{3}{*}{ Fígado } & \multirow{3}{*}{ Bile } & Bílica \\
\hline & & É o detergente \\
\hline & & Tirar a gordura \\
\hline \multirow[b]{2}{*}{$\begin{array}{l}\text { Vesícula } \\
\text { Biliar }\end{array}$} & Vesícula biliar & Visúlica \\
\hline & $\begin{array}{l}\text { Ductos que faz a conexão com o } \\
\text { intestino }\end{array}$ & É para produzir o detergente \\
\hline $\begin{array}{l}\text { Intestino } \\
\text { delgado }\end{array}$ & Absorção & Tem um monte de mangueirinha \\
\hline \multirow{3}{*}{$\begin{array}{l}\text { Intestino } \\
\text { Grosso }\end{array}$} & Forma as fezes & Ele vai e faz uma sucção final \\
\hline & Apêndice & $\begin{array}{l}\text { Ele é só pra finalizar o liquido e essas } \\
\text { coisas }\end{array}$ \\
\hline & Apendicite & $\begin{array}{l}\text { Ele suga a água e depois ele devolve a } \\
\text { água }\end{array}$ \\
\hline
\end{tabular}

Fonte: Elaboração própria 
Os grupos 2 e 3 afirmaram que a principal função dos intestinos era a absorção de nutrientes. O grupo 1 apresentou dificuldade nesse ponto, dentre as falas deste grupo chamou a atenção a seguinte afirmação: "Ele suga a água e depois ele devolve a água", portanto, conclui-se que não conseguiram formular uma resposta adequada, já que o intestino não tem a função de devolver água. Um sujeito do grupo 2 na intenção de explicar como era este órgão, disse: "É o que tem um monte de mangueirinha assim" gesticulando com a mão movimentos horizontais em ziguezague. Outra afirmação interessante foi de um sujeito do grupo 3: "ele vai e faz uma sucção final", relacionando o intestino grosso com a absorção de água. O que chamou a atenção foi que, para expressar o conhecimento, os sujeitos imaginaram e criaram associações diferentes às explicadas na exposição. Diferentemente, os relatos referentes ao estômago e a vesícula biliar foram semelhantes às associações lúdicas que os mediadores utilizaram para que os visitantes compreendessem os fenômenos biológicos. A atividade de aprender com o lúdico pode proporcionar ao indivíduo maior capacidade de reflexão, tendo em vista que Chateau (1987) afirmou que uma criança que não sabe construir ideias e/ou desenvolver a cognição através do imaginário será um adulto que não sabe pensar.

Ao fim da pesquisa, averiguou-se com os relatos colhidos, que a exposição contribuiu de forma significativa para a construção do conhecimento, cujos sujeitos formularam ideias sobre o funcionamento do sistema digestório. De acordo com Falcão et al. (2003), a aprendizagem é um processo que ocorre a longo prazo envolvendo progressos e regressões e não uma simples substituição de ideias. Bizerra e Marandino (2009) afirmaram que o conhecimento é dinâmico e ininterrupto, acontecendo a todo momento em contextos anterior e posterior à visita. Em concordância com essas concepções, não se pode afirmar que as ideias expressadas na roda foram por consequência da visitação a exposição, mas sim que o espaço contribuiu para o alfabetismo científico como analisado nos relatos descritos.

\section{Lembranças dos visitantes sobre a exposição "Comer para Viver"}

Para todos os grupos, as últimas perguntas da roda de conversa foram para estimular os sujeitos a expressarem o que lembravam e o que mais chamou a atenção deles. Neste momento, deixou-se que os sujeitos relatassem qual o conteúdo lhes instigou a curiosidade e, também, estimulou a necessidade de repassar, para os familiares e amigos, o que aprendeu.

No primeiro grupo, foi questionado se após a exposição, lembravam das explicações sobre a alimentação e o formato das fezes. Todos balançaram a cabeça em sinal afirmativo e deram risadas. Um sujeito quis saber sobre a desidratação na citação a seguir, a qual foi esclarecida pela mediadora:

[...] deixa eu te fazer uma pergunta, pra ver se é verdade. Dizem que quando a gente está muito desidratado não é só no xixi que dá pra você vê. Se você fizer isso aqui (e fez uma prega na pele da mão), e ela for devagarzinho, tá muito desidratado. Mas, se você puxar assim (e fez a prega novamente), e ela for bem rápido, é porque você está hidratado.

Um estudante comentou que: "Eu falei pro meus pais tudo que eu tinha visto lá. Das bactérias, dos vermes". Posteriormente, outro participante disse: "Eu gostei do que o rapaz falou da diabete e dos vermes. Eu achei interessante o negócio dos 
vermes". Como eles falaram bastante dos vermes, foi perguntado onde esses microorganismos ficavam no nosso corpo, tendo se expressado dois sujeitos: "No estômago? No intestino?" e "Ele come nossas comidas". A mediadora interveio, perguntando como podemos cuidar da nossa saúde, para que esses bichos não morem no intestino, obtendo várias respostas: "Lavando a mão", "Lavando bem os alimentos", "Não fazer cocô no mato, [...] tem uns animais que pode comer e depois a gente come eles" e "Acho que não pode comer a carne vermelha [...] mal passada".

Um sujeito fez uma pergunta sobre o que era a glicose, sendo respondido pela responsável da condução da roda de conversa. Logo a seguir, um sujeito narrou que achou interessante uma imagem que estava exposta: "Aquela! Que tá o professor lá! Mostrando no homem! E depois, o Franjinha faz no coelhinho", se referindo a paródia da obra "A lição de Anatomia do Dr. Tulp" do ano de 1632, na qual o Maurício de Souza desenhou com os personagens da Escolinha da Mônica (Figura 2).

Figura 2 - Painéis da exposição "Comer para viver" realizada na Universidade Federal de Mato Grosso campus Sinop, destacando o banner "A lição de anatomia do Dr Tulp e Dr Franjinha" de 1632.

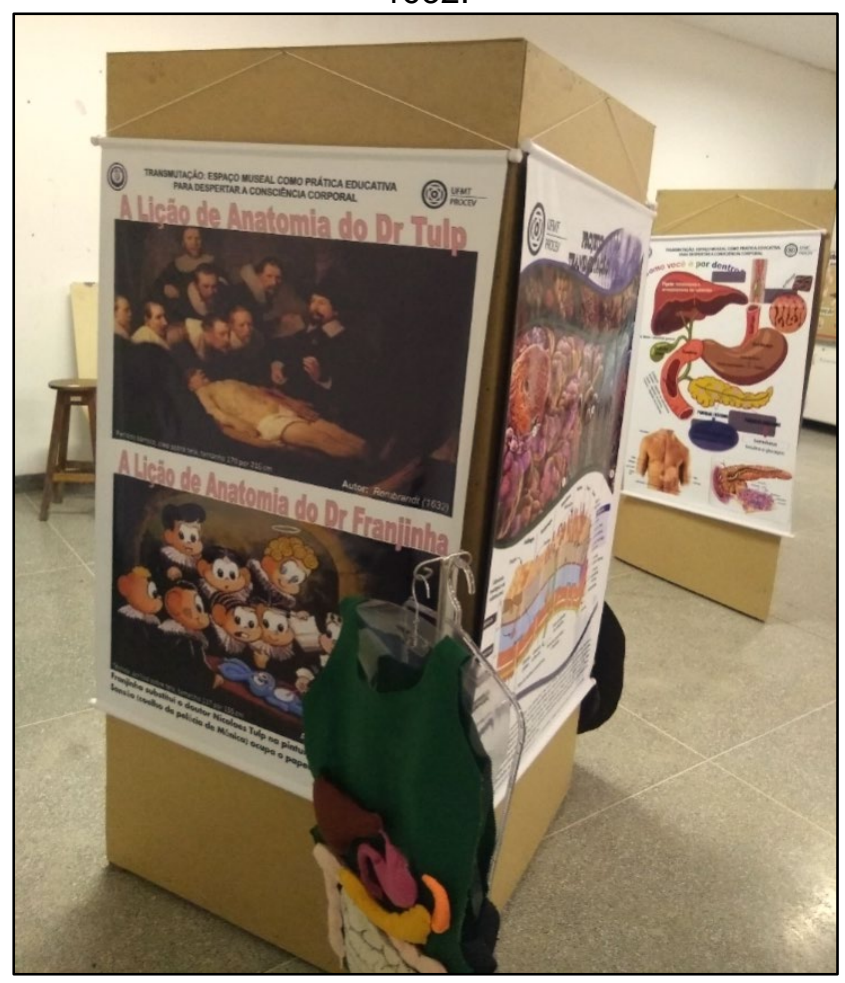

Fonte: Elaboração própria

Também foram citados os gases por um dos participantes da pesquisa, mas ele não soube explicar sua ideia. A mediadora perguntou se eles lembravam da composição dos gases e ninguém respondeu. Sobre os alimentos que deixavam os gases fétidos, um integrante afirmou que era o ovo, o repolho, dentre outros, mas, não conseguiram correlacionar os compostos químicos.

No segundo grupo, um sujeito narrou que achou interessante a parte: "Da merda. Se iria boiar ou não. Eu contei pra minha irmã. E diz ela, que toda vez que vai no banheiro fica olhando o cocô". Outro sujeito disse que os vermes chamaram a sua 
atenção, depois afirmou: "Eles não pode ficar no nosso corpo, porque faz mal pra saúde".

No terceiro grupo, um sujeito afirmou: "Gostei da parte da lombriga. A solitária tem um conjunto de curvinhas, que vai ligando". A mediadora perguntou a este, o que aprendeu sobre a solitária e onde parasitava. O mesmo indivíduo respondeu: "No intestino", logo a seguir outro integrante do grupo complementou: "É porque, não é bom que elas moram ali, porque elas absorve os nutrientes que a gente come". Mediante esta afirmação, perguntou-se como estes parasitas chegavam no intestino, recebendo a seguinte resposta: "Por alimentos contaminados. Carne mal passada, de porco, principalmente, o boi também".

Seguindo a escuta dos relatos, um participante disse: "Eu achei legal a parte das fibras. E tem também o quadro da anatomia. Gostei do jeito, né, que eles faz a anatomia. O estudo do corpo, sei lá. Eu gostei da parte do quadro que a turma da Mônica, estava repetindo do mesmo jeito a parte de cima". Por fim, outro integrante do grupo afirmou: "Quando eu cheguei na escola, eu não peguei no corrimão, por causa das bactérias. E não comi mais carne mal passada".

Alguns fatores que contribuíram para a riqueza nos relatos se atribuiu a transposição museográfica e didática da exposição. Nesse aspecto, Souza (2015) chama essa organização de design e relata que essa configuração nos espaços museais são imprescindíveis para despertar o interesse e a curiosidade dos visitantes. Sendo assim, conforme esta autora, a compreensão e apropriação são influenciadas pelo design.

De acordo com Rocha (2008), as lembranças dos indivíduos sobre a visitação constituem uma maneira de aprender, juntamente com a significação dos ensinamentos aprendidos associados ao cotidiano. Na mesma linha de defesa, Souza (2015) afirmou que, ao visitar uma exposição, o conhecimento prévio associado ao interesse em aprender e aos valores culturais são aspectos particulares de cada indivíduo, tornando o ato de aprender peculiar. A experiência da visitação ao espaço não formal pelos sujeitos da pesquisa, juntamente com os fatores mencionados por Rocha (2008) e Souza (2015), influenciaram na apropriação do conhecimento. Falk e Dierking (1992) ressaltaram que os eventos posteriores à visita também são importantes neste processo. Dessa forma, a roda de conversa foi conduzida para extrair as lembranças que mais marcaram os sujeitos pesquisados, atentando-se, também, para possíveis alterações no hábito de vida, considerado um fator potencial para o processo educativo desses indivíduos.

Alguns relatos expressaram a importância de não comer alimentos crus, como forma de prevenir a contaminação e até mesmo doenças causadas por parasitas. A forma das fezes e a cor da urina funcionam como indicadores de boa alimentação e hidratação, respectivamente. Futuramente, esses conceitos poderão ser reformulados pelos sujeitos, quando em contato com novas formas de abordagem deste conteúdo, ou até mesmo promover mudanças de hábito. Corroborando a declaração de Hipócrates no ano de 2.300 a.C., sobre o funcionando do encéfalo na qual, os cidadãos são capazes de aprender e modificar seu comportamento a partir de experiências acumuladas ao longo da vida (COSENZA, GUERRA, 2011). Assim, para modificar a sociedade deve-se oportunizar a educação, porque de acordo com a Organização Mundial de Saúde (OMS), a saúde é reconhecida como 
o maior e melhor recurso para o desenvolvimento social, econômico e pessoal de um país.

Uma das mais impressionantes funções do encéfalo é a capacidade de armazenar informações adquiridas com a experiência e poder evocá-las de forma intencional ou voluntária (SOUZA, 2015). Esta autora também afirmou que a palavra "memória" é a habilidade do sistema nervoso central em de adquirir, registrar e evocar informações. Dessa forma, considera-se que os seres humanos conseguem acumular diferentes experiências ao longo da vida. De acordo com alguns neurocientistas, o sistema nervoso central (SNC) possui vários tipos de memória. Dentre elas, destaca-se a memória, na qual as mensagens são processadas momentaneamente e não arquivadas, sendo esquecidas depois de um tempo (IZQUIERDO, 2002) e a memória utilizada para armazenar o conteúdo processado a longo prazo, assim, não sendo esquecida (PURVES et al., 2010). Nessa linha de pensamento, tudo que é lembrado é porque foi absorvido e armazenado no SNC.

Os sujeitos pesquisados relataram as experiências mais marcantes vivenciadas durante a exposição. Portanto, afirma-se que esses resultados são frutos das recordações, ou seja, as informações absorvidas, processadas e armazenadas pelo SNC, podendo estas serem evocadas para contribuir na manutenção da saúde desse indivíduo. Este fenômeno foi de extrema importância, já que o indivíduo precisa ser ativo no processo da promoção de saúde, como recomendação pelo programa de Educação e Saúde Popular do Ministério da Saúde via ações preventivas. Paulo Freire (2005) afirmou não ser eficaz o método no qual o educador estimula somente a reprodução do conhecimento, de forma que os educandos assumem uma postura passiva no processo de ensino aprendizagem. Os indicadores de obesidade, doenças crônicas, dentre outras, nos quais podem ser oriundas de uma má alimentação crescem constantemente, desta forma faz-se necessário ações preventivas nas quais os sujeitos sejam ativos.

Alguns autores, como o Izquierdo (2002) e Kandel (2014), mencionaram em suas pesquisas que o processo de adquirir, consolidar e armazenar informações é muito influenciado por alguns elementos presente nos indivíduos, como ânimo, estado de alerta e pelas emoções. Izquierdo, Bevilaqua e Cammarota (2006), afirmaram ser mais fácil aprender quando se está emocionado ou em estado de alerta, do que quando não há interesse. Nesse sentido, a probabilidade de serem gravadas as experiências que tenham maior carga emocional é maior quando comparada a outras sem envolvimento emocional. Spitzer (2007) justificou que esse fenômeno ocorre porque as emoções estimulam a liberação de neurotransmissores, como a dopamina, os quais geram uma sensação de bem-estar e disposição, mobilizando a atenção do sujeito para o que está sendo apresentado. Por esse motivo, as exposições científicas se constituem um local potencial para promover a aprendizagem, visto que os materiais didáticos, o ambiente e a organização do espaço são capazes de incitar, não só a curiosidade, como também, motivar a aprendizagem. Além do que, a utilização do lúdico nesses ambientes, pode ser uma estratégia que potencialize o alcance do objetivo de apropriação do conhecimento pelo visitante, conforme os dados coletados na pesquisa relacionados sobre a análise morfológica do sistema digestório, corpo saudável e os relatos das lembranças.

Ao considerar que o aprendizado é de responsabilidade do indivíduo, as exposições científicas são estruturadas para facilitar este processo. Assim, é correto dizer que 
quando o curador prepara o conteúdo de uma exposição, tem se a expectativa de que o público aprenda sobre a temática proposta. No entanto, nem tudo o que é disponibilizado será assimilado pelo público, porque o aprender é livre e o visitante tem o poder de escolher se dará importância ou não ao que está exposto (FALK; STORKSDIECK, 2005). Por consequência, os sujeitos da pesquisa descreveram recordações distintas. Ao observar os resultados com cautela, verificou-se, em todos os grupos, a repetição de falas sobre os vermes, o que pode ser explicado pelo fato da habilidade da mediadora da exposição em trabalhar este conteúdo, associado ao uso da lupa para ampliar a imagem projetada no computador destes parasitas, ou pode ter sido influenciada por outros fatores, como por exemplo, o conhecimento prévio.

Quando se pesquisa a influência de uma exposição científica nos visitantes, Falk e Storksdieck (2005) ponderam que não se deve considerar importante somente as lembranças fruto da aprendizagem, mas, também, é interessante saber se o conteúdo está sendo aplicado na prática cotidiana do indivíduo. Dessa forma, pesquisar a aplicação da teoria na prática foi muito importante para desvendar se os sujeitos além de serem alfabetizados cientificamente, também, foram letrados cientificamente. A partir de algumas falas foi possível observar que os sujeitos conseguiram fazer essa correlação, como por exemplo, associando o modo de consumo dos alimentos para evitar doenças e as fezes como indicativo de alimentação saudável. Além de alguns sujeitos expressarem mudança de hábito devido à preocupação com a contaminação do corpo por micro-organismos existentes na mão.

Leitão e Pavão (2007) apontaram que uma exposição deve oferecer respostas e também despertar outros questionamentos, para que, após a visitação, se continue a busca por outras fontes de conhecimento. Na roda de conversa, foi possível vivenciar essa experiência, como no caso dos gases onde os sujeitos relataram que acharam o tema interessante, todavia, não conseguiram explicar os conceitos. Acredita-se que foi porque ainda não tiveram o conteúdo de química na escola. Outro exemplo, foi quando um sujeito questionou sobre os sinais de desidratação no corpo, dizendo que este processo não era percebido somente pela coloração da urina, mas também, pelo teste das pregas da pele. Esse assunto não foi abordado na exposição, mas surgiu o interesse em saber mais sobre ele, sendo necessário a intervenção da mediadora para explicar essa avaliação cutânea. Estes resultados corroboraram a visão dos autores supracitados de que a exposição deve despertar outros questionamentos, estimulando a formação da criticidade e colaborando para formar cidadãos.

Outra lembrança importante mencionada foi a paródia que Maurício de Souza fez do quadro "A lição de anatomia do Dr. Tulp", pintura de Rembrandt de 1632, na qual alguns sujeitos mencionaram que acharam interessante os integrantes da turma da Mônica estudarem o corpo humano, o que poderia significar o desejo deles em ingressar na Universidade. No Brasil, muitas pessoas nem cogitam a possibilidade de fazer um curso superior. Dessa maneira, estar em contato com o ambiente universitário e o espaço científico não formal da exposição, pode contribuir para novas descobertas e estimular a mudança de concepção dos visitantes, ampliando a perspectiva desses sujeitos para planejar o seu futuro, desfazendo rótulos sociais implantados pela sociedade. 


\section{Considerações finais}

Este trabalho surgiu do interesse em compreender o quanto a interação dos visitantes com o espaço não formal de aprendizado poderia significar para a apropriação do conhecimento sobre o sistema digestório e alimentação.

A exposição "Comer para viver" oportunizou a divulgação científica e a popularização do conhecimento, porque pela análise das falas dos estudantes percebeu-se que eles se apropriaram dos conceitos científicos e até divulgaram o que aprenderam entre os seus familiares. Alguns participantes inclusive relataram mudanças de hábito após visitar a exposição.

\section{Referências}

ANDERSON, D.; LUCAS, K. B.; GINNS, I. S. Theoretical perspectives on learning in an informal setting. Journal of Research in Science Teaching, Hoboken, v. 40, n. 2 2 p. 177-199, 2003. Disponível em: https://onlinelibrary.wiley.com/doi/abs/10.1002/tea.10071. Acesso em: 15 fev. 2020.

BARDIN, L. Análise de conteúdo. São Paulo: Edições 70, 2011.

BAKER, D. W. et al. Health literacy and the risk of hospital admission. J Gen Intern Med. v. 13, n. 12, p. 791-8, dez. 1998. Disponível em: https://www.ncbi.nlm.nih.gov/pubmed/9844076. Acesso em: 04 mai. 2020.

BIZERRA, A. F.; MARANDINO, M. A concepção de aprendizagem nas pesquisas em educação em museus. In: Anais do VII Encontro Nacional de Pesquisa em Educação em Ciências- ENPEC, Florianópolis, 2009. Disponível em: http://posgrad.fae.ufmg.br/posgrad/viienpec/pdfs/541.pdf. Acesso em: 19 fev. 2020.

BIZERRA, A. F. Atividade de Aprendizagem em Museus de Ciências. 2009. 274 f. Tese (Doutorado em Ensino de Ciência e Matemática)-Faculdade de Educação da Universidade de São Paulo, São Paulo, 2009. Disponível em: http://www.teses.usp.br/teses/disponiveis/48/48134/tde-15092009-132843/ptbr.php. Acesso em: 20 fev. 2020.

BRASIL. Ministério da Saúde. Secretaria de Gestão do Trabalho e da Educação na Saúde. Glossário temático: gestão do trabalho e da educação da saúde. Brasília-DF, 2012. Disponível em: bvsms.saude.gov.br/bvs/publicacoes/glossario_sgtes.pdf. Acesso em: 13 fev. 2020 .

BRASIL. Ministério da Educação. Secretaria de Educação Básica. Secretaria de Educação Continuada, Alfabetização, Diversidade e Inclusão. Secretaria de Educação Profissional e Tecnológica. Conselho Nacional da Educação. Câmara Nacional de Educação Básica. Base Nacional Comum Curricular - BNCC. Diretoria de Currículos e Educação Integral. Brasília-DF: MEC, SEB, DICEI, p. 2019. Disponível em: http://basenacionalcomum.mec.gov.br/images/BNCC_El_EF_110518_versaofinal_ site.pdf. Acesso em: 25 fev. 2020.

BORTOLETTO, L. Museus e centros de ciências como espaços educativos não formais, 2013. Atas do IX Encontro Nacional de Pesquisa em Educação em Ciências - IX ENPEC, Águas de Lindóia - SP, 2013. Disponível em: 
http://www.nutes.ufrj.br/abrapec/ixenpec/atas/resumos/R1442-1.pdf. Acesso em: 31 jan. 2020.

CARIBÉ, R. de C. do V. Comunicação científica para o Público leigo no Brasil. 2011. 320 f. Tese (Doutorado em Ciência da Informação)-Universidade de Brasília, Brasília-DF, 2011. Disponível em: http://repositorio.unb.br/bitstream/10482/9003/1/2011_RitadeC\%C3\%A1ssiadoVal eCarib\%C3\%A9.pdf. Acesso em: 19 fev. 2020.

CARVALHO. G. S. Literacia científica: Conceitos e dimensões. In: Modelos e práticas em literacia. AZEVEDO, F.; SARDINHA, M. G. (Coord.), Lisboa: Lidel, p. 179-194, 2009. Disponível em: https://repositorium.sdum.uminho.pt/bitstream/1822/9695/1/LIDEL_Literacia\%20cie ntifica.pdf. Acesso em: 08 fev. 2020.

CAZELLI, S.; MARANDINO, M.; STUDART, D. Educação e Comunicação em Museus de Ciências: aspectos históricos, pesquisa e prática In: Educação e Museus: A construção social do caráter educativo dos museus de ciências. GOUVEIA, G; MARANDINO, M.; LEAL, M. (orgs.), Access Editora, Rio de Janeiro, $2003 . \quad$ Disponível em: https://edisciplinas.usp.br/pluginfile.php/844165/mod_resource/content/1/CAZELLI MARANDINO_STUDART_Educa\%C3\%A7\%C3\%A33o_\%20Comunica\%C3\%A7\% C̄3\%A3o_em_Museus_de_Ci\%C3\%AAncia.pdf. Acesso em: 09 fev. 2020.

COSENZA, R.; GUERRA, L. Neurociência e Educação. Porto Alegre: Artmed, 2011.

CRUZMAN, C.; SIQUEIRA, V. H. F. O papel educacional do Museu de Ciências:desafios e transformações conceituais. Revista Electrónica de Enseñanza de las Ciencias, Rio de Janeiro, v. 6, n. 2, p. 402-423, 2007. Disponível em: http://reec.uvigo.es/volumenes/volumen6/ART10_Vol6_N2.pdf. Acesso em: 09 jan. 2020.

CHATEAU, J. O jogo e a criança. 4 ed. São Paulo: Summer, 1987.

FIGUEROA, A. M. S.; MARANDINO, M. Os modelos pedagógicos na aprendizagem em museus de ciências. Atas do IX Encontro Nacional de Pesquisa em Educação em Ciências - IX ENPEC Águas de Lindóia, 2013. Disponível: http://www.nutes.ufrj.br/abrapec/ixenpec/atas/resumos/R0994-1.pdf. Acesso em: 06 jan. 2020.

FALCÃO, D. et al. Museus de Ciências, Aprendizagens e modelos mentais: Identificando Relações. In: Educação e Museus: A construção social do caráter educativo dos museus de ciências. GOUVEIA, G; MARANDINO, M.; LEAL, M. (orgs.), Access Editora, Rio de Janeiro, 2003.

FALK J. H.; DIERKING, L. D. The musem experience. Washington: DC Whalesback Books, 1992.

FALK, J. H.; STORKSDIECK, M. Learning science from museums. Hist. cienc. saude-Manguinhos, Rio de Janeiro, v. 12, supl. p. 117-143, 2005. Acesso em: http://www.scielo.br/scielo.php?script=sci_arttext\&pid=S010459702005000400007\&lng=en\&nrm=iso. Disponível em: 04 jan. 2020.

ICOM. Conselho Internacional de Museus, 2015. Disponível em: http://icomportugal.org/2015/03/19/definicao-museu/. Acesso em: 20 jan. 2020. 
IZQUIERDO, I. Memória. Porto Alegre: Artmed, 2002.

IZQUIERDO, I.; BEVILAQUA, L. R. M.; CAMMAROTA, M. A arte de esquecer. Estud. av., São Paulo, v. 20, n. 58, p. 289-296, set./dez. 2006. Disponível em: http://www.scielo.br/scielo.php?script=sci_arttext\&pid=S010340142006000300024\&Ing=en\&nrm=iso. Acesso em: 02 fev. 2020.

KANDEL, E. R. et al. Princípios de Neurociências. 5 ed. Porto alegre: Artmed, 2014.

LEITÃO, A.; PAVÃO, A. C. Hands-on? Minds-on? Hearts-on? Social-on? Explainers-on! In: Diálogos \& ciência: mediação em museus e centros de Ciência. Organizado por MASSARANI, L.; MERZAGORA, M.; RODARI, P. - Rio de Janeiro: Museu da Vida. Casa de Oswaldo Cruz, Fiocruz, 2007. Disponível em: http://www.fiocruz.br/omcc/media/EVCV_KOPTCKE_Analisando_a_dinamica.pdf . Acesso em: 29 jan. 2020.

LIBÂNEO, J. C. Pedagogia e pedagogos, para quê? 7 ed. São Paulo: Cortez, 2004.

MATOS, I. A. P. de. Educaçãomuseal: o caráter pedagógico do museu na construção do conhecimento. Brazilian Geographical Journal: Geosciences and Humanities research medium, Ituiutaba, v. 5, n. 1, p. 93-104, jan./jun. 2014. Disponível em: http://www.seer.ufu.br/index.php/braziliangeojournal/article/view/23630. Acesso em: 31 jan. 2020.

MCMANUS, P. Investigation of exhibition team behaviors and the influences on them: towards ensuring that planned interpretations come to fruition. In: DUFRESNE-TASSÉ, C. (org.). Cultural Diversity, Distance and Learning. Montréal: Université de Montréal, 2000, p.182-189. --------. Topics in museums and science education. Studies in Science Education, n. 20, p. 157-182. 1992.

MOREIRA, M. A. Teoria de aprendizagem. São Paulo: ed pedagógica Universitária, 1999.

OLIVEIRA, N. Atividades de experimentação investigativas lúdicas no Ensino de Química: um estudo de caso. 2009. 147 f. Tese (Doutorado em Química do Cerrado e Pantanal) - Universidade Federal de Goiás, Goiânia, 2009. Disponível em:

https://repositorio.bc.ufg.br/tede/bitstream/tde/1025/1/Tese $\% 20$ Noe\%20de\%20Oliv eira\%20Doutorado\%20em\%20Quimica1.pdf. Acesso em: 06 fev. 2020.

FREIRE, P. Pedagogia do Oprimido. 42 ed. Rio de Janeiro: Paz e Terra, 2005.

PURVES, D. et al. Neurociências. 4 ed. Porto Alegre: Artmed, 2010.

PASKULIN, L. M. G. et al. Alfabetização em saúde de pessoas idosas na atenção básica. Acta Paul Enferm, v. 25, n. 1, p. 129-35, 2012. Disponível em: http://www.scielo.br/pdf/ape/v25nspe1/pt_20.pdf. Acesso em: 06 fev. 2020.

ROCHA, V. A contribuição da visita ao museu da vida para a formação de concepções sobre saúde e ambiente: uma experiência com jovens do projeto ciência e sociedade. 2008. 198 f. Dissertação (Mestrado de Ensino em Biociência e Saúde) - Instituto Oswaldo Cruz, Rio de Janeiro, 2008. Disponível em: 
http://www.fiocruz.br/brasiliana/cgi/cgilua.exe/sys/start.htm?infoid=367\&sid=27. Acesso em: 06 fev. 2020.

SANTOS, S. C. A importância do lúdico no processo ensino aprendizagem. Monografia (Especialização em gestão educacional-Universidade Federal de Santa Maria, Santa Maria, 2010. Disponível em: https://repositorio.ufsm.br/bitstream/handle/1/393/Santos_Simone_Cardoso_dos.p df. Acesso em: 28 jan. 2020.

SOUZA, V. M., de. Memória e museus de ciências: a compreensão de uma experiência museal a partir da recuperação das memórias dos visitantes. 2015. 164 f. Dissertação (Mestrado em Educação em Ciências e Matemática)-Pontifícia Universidade Católica do Rio Grande do Sul, Porto alegre, 2015. Disponível em: http://tede2.pucrs.br/tede2/bitstream/tede/6167/2/470937\%20\%20Texto\%20Completo.pdf . Acesso em: 25 jan. 2020.

SUANO, M. O que é museu. São Paulo: Brasiliense, 1986.

SCHEINER, T. C. O museu como processo. In: cadernos de diretrizes museologicas 2: mediação em museu: curadorias, exposições, ação educativa. BITTENCOURT, J. N. (Org.). Belo Horizonte, 2008. Disponível em: http://www.cultura.mg.gov.br/files/museus/1caderno_diretrizes_museologicas_2.pd f. Acesso em: 16 fev. 2020.

SOARES, M. Letramento: um tema em três gêneros. 3 ed. São Paulo: Autêntica, 2007.

SORENSEN, K. et al. Health literacy and public health: a systematic review and integration of definitions and models. BMC Public Health. v. 25, n. 80, 2012. Disponível em: https://bmcpublichealth.biomedcentral.com/articles/10.1186/14712458-12-80. Acesso em: 14 fev. 2020.

SPITZER, M. Aprendizagem: neurociências e a escola da vida. Lisboa: Climepsi, 2007.

VASCONCELOS, Y. L.; MANZI, S. Processo ensino-aprendizagem e o paradigma construtivista. Interfaces Científicas - Educação, Aracaju, v. 5, n. 3, p. 66-74, jun. 2017.

Disponível em:

https://periodicos.set.edu.br/index.php/educacao/article/viewFile/3238/2329.

Acesso em: 28 fev. 2020. 
Recebido: $21 / 02 / 20$

Aprovado: $16 / 10 / 20$

Como citar: OLIVEIRA, W. C.; REZENDE, L. C.; SILVA, C. M. B. O uso da exposição científica "Comer para viver" como atividade não formal para educação em saúde. Revista de Estudos e Pesquisas sobre Ensino Tecnológico (EDUCITEC), v. 6, e101920, 2020.

Direito autoral: Este artigo está licenciado sob os termos da Licença Creative CommonsAtribuição 4.0 Internacional.

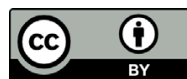

